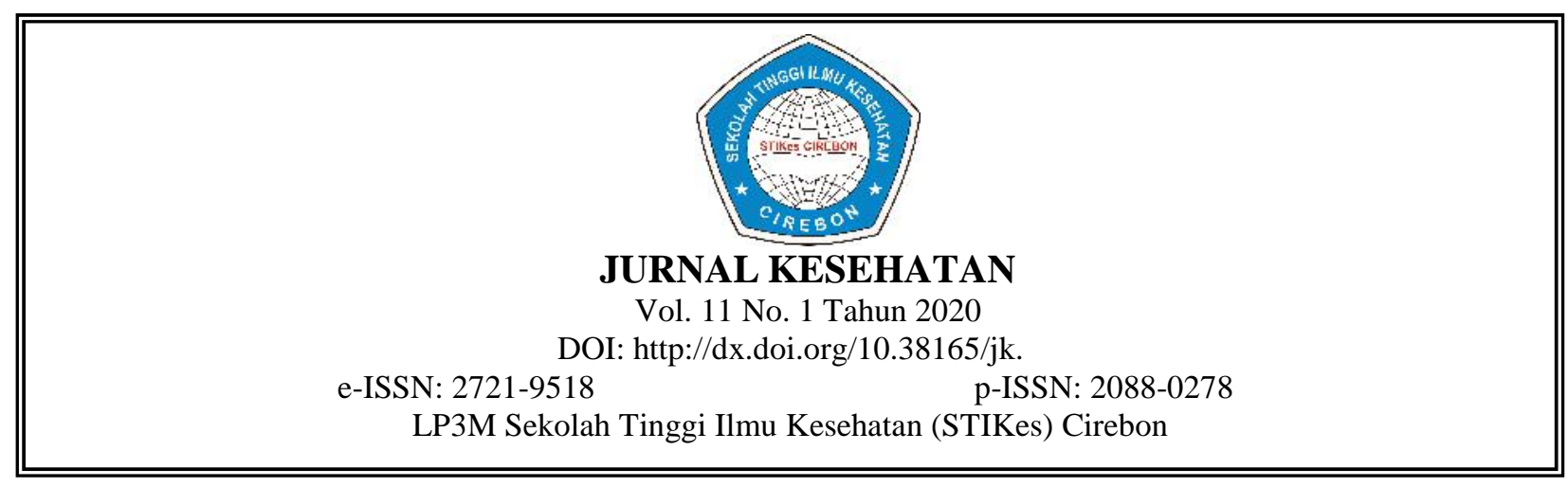

\title{
FAKTOR YANG BERHUBUNGAN DENGAN PENGETAHUAN KADER POSYANDU TENTANG 1000 HARI PERTAMA KEHIDUPAN (HPK)
}

\author{
Lambang Satria Himmawan * \\ Program Studi Kesehatan Masyarakat, Universitas Mathla'ul Anwar Banten \\ lambang_83@yahoo.co.id
}

\begin{abstract}
Abstrak
Salah satu gerakan percepatan perbaikan gizi yang didapatkan dari adopsi gerakan Scalling up-Nutrition (SUN) Movement adalah Periode 1000 Hari Pertama Kehidupan. Gerakan Scaling Up-Nutrition (SUN) Movement merupakan suatu gerakan global di bawah koordinasi Sekretaris Jenderal PBB. Hadirnya gerakan ini merupakan respons dari negara-negara di dunia terhadap kondisi status pangan dan gizi di negara berkembang. Tujuan utama dari Scalling UpNutrition (SUN) Movement adalah untuk menurunkan masalah gizi pada 1000 Hari Pertama Kehidupan yaitu proses dari awal kehamilan sampai usia 2 tahun. Terbukti secara ilmiah bahwa Periode 1000 HPK ini merupakan periode yang menentukan kualitas kehidupan seseorang, oleh karena itu periode ini sering disebut sebagai Golden Periode atau "periode emas". Maka jika pada rentang usia tersebut anak mendapatkan asupan gizi yang optimal maka penurunan status gizi anak bisa dicegah sejak awal. Kader posyandu sebagai salah satu ujung tombak kesehatan masyarakat di Desa mempunyai tugas menjadi jembatan antara masyarakat desa dengan petugas kesehatan, maka kader posyandu harus mempunyai pengetahuan yang baik tentang kesehatan salah satunya tentang Gizi dan 1000 HPK. Tujuan penelitian ini adalah untuk mengetahui faktor yang berhubungan dengan pengetahuan kader tentang 1000 HPK.

Jenis penelitian yang digunakan adalah explanatory research. Metode penelitian yang digunakan adalah survei analitik dengan pendekatan cross sectional. Pada penelitian ini populasi dan sampelnya adalah seluruh Kader Posyandu di Desa Cigeulis Kecamatan Cigeulis sejumlah 19 orang.

Hasil penelitian $68,4 \%$, kader posyandu mempunyai pengetahuan rendah tentang $1000 \mathrm{HPK}, 73,7 \%$ kader mempunyai pendidikan rendah. $84,2 \%$ kader posyandu berusia matang, cenderung tua. 63,2\% kader posyandu mempunyai masa pengabdian/masa kerja lama ( $>5$ tahun). Hasil statistik didapatkan hasil terdapat hubungan antara pendidikan dengan pengatahuan kader posyandu tentang 1000 HPK. Tidak Terdapat hubungan antara usia dengan pengatahuan kader posyandu tentang $1000 \mathrm{HPK}$. Dan tidak terdapat hubungan antara lama pengabdian dengan pengatahuan kader posyandu tentang 1000 HPK.
\end{abstract}

Kata kunci: 1000 HPK, kader posyandu.

\begin{abstract}
One of the movements to accelerate nutritional improvement obtained from the adoption of the Scaling Up-Nutrition (SUN) Movement is the First 1000 Days of Life Period. The Scaling Up-Nutrition (SUN) Movement is a global movement under the coordination of the UN Secretary General. The presence of this movement is a response from countries in the world to the condition of food and nutrition status in developing countries. The main purpose of the Scaling Up-Nutrition (SUN) Movement is to reduce nutritional problems in the First 1000 Days of Life, which is the process from the beginning of pregnancy until the age of 2 years. Scientifically proven that the First 1000 Days of Life is a period that determines the quality of a person's life, therefore this period is often referred to as the Golden Period or "golden period" So if in that age range the child gets the optimal nutritional intake then a decrease in the nutritional status of the child can be prevented from the start. Posyandu cadres as one of the spearheads of community health in the village have the task of being a bridge between the village community and health workers, so posyandu cadres must
\end{abstract}


have good knowledge about health, one of them is about nutrition and the First 1000 Days of Life Period. The purpose of this study was to determine the factors associated with cadre knowledge about the First 1000 Days of Life (1000 HPK). The type of research used was explanatory research; the research method used was an analytic survey with cross sectional approach. In this study the population and sample were all Posyandu cadres with 19 people. The results of the study were $68.4 \%$, posyandu cadres had low knowledge about the first 1000 days of life (1000 HPK), and 73.7\% cadres had low education. $84.2 \%$ of Posyandu cadres are mature, tend to be old. $63.2 \%$ posyandu cadres have a long term of service (> 5 years). The statistical results show that there is a relationship between educations with the knowledge of posyandu cadres about the first 1000 days of life (1000 HPK), there is no relationship between age and posyandu cadre knowledge about the first 1000 days of life (1000 HPK). And there is no relationship betweenthe length of service and knowledge of the cadre.

Keywords: The First 1000 Days of Life, posyandu cadre 


\section{PENDAHULUAN}

Salah satu gerakan percepatan perbaikan gizi yang didapatkan dari adopsi gerakan Scalling Up-Nutrition (SUN) Movement adalahPeriode 1000 Hari Pertama Kehidupan. Gerakan Scaling UpNutrition (SUN) Movement merupakan suatu gerakan global di bawah koordinasi Sekretaris Jenderal PBB. Hadirnya gerakan ini merupakan respons dari negara-negara di dunia terhadap kondisi status pangan dan gizi di negara berkembang. Tujuan utama dari Scalling Up-Nutrition (SUN) Movement adalah menyelamatkan generasi yang akan datang dengan melindungi dan mencegah kelompok 1000 HPK dari masalah gizi dan kesehatan masyarakat, untuk menurunkan masalah gizi pada 1000 Hari Pertama Kehidupan yaitu proses dari awal kehamilan sampai usia 2 tahun. Terbukti secara ilmiah bahwa Periode 1000 HPK ini merupakan periode yang menentukan kualitas kehidupan seseorang, oleh karena itu periode ini sering disebut sebagai Golden Periode atau "periode emas" atau "periode kritis" dan Bank Dunia menyebutnya sebagai "window Opportunity". 1

Stunting atau terhambatnya pertumbuhan tubuh merupakan salah satu bentuk kekurangan gizi yang ditandai dengan tinggi badan menurut umur dibawah $(<-2$ SD) standar deviasi dengan referensi WHO 2005. Stunting disebabkan oleh beberapa faktor seperti kurangnya asupan ibu pada saat hamil, pola asuh yang tidak tepat. Kejadian stunting pada anak merupakan suatu proses kumulatif yang terjadi sejak kehamilan, masa kanak-kanak dan sepanjang siklus kehidupan. ${ }^{2}$

Menurut USAID Status Gizi ibu hamil dan menyusui, status kesehatan dan asupan gizi yang baik selama masa kehamilan hingga tahun pertama kehidupan anak berperan dalam membentuk fungsi otak hingga membantu memperkuat system imun. Ibu hamil dengan gizi kurang akan menyebabkan janin mengalami Intrauterine Growth Retardation (IUGR), sehingga bayi akan lahir dengan kurang gizi, dan mengalami gangguan pertumbuhan dan perkembangan serta mudah untuk terkena penyakit degeneratif saat dewasa kelak (fetal origin desease). ${ }^{3}$

Di lihat dari indikator masalah kinerja program Gizi provinsi Banten, terjadi peningkatan persentase kejadian stunting. Pada tahun 2016 persentase kejadian stunting hanya 27,0\%. Sedangkan pada tahun 2017 sebesar 29,6\%. Hal tersebut juga terjadi di Kabupaten Pandeglang, dimana kasus balita stunting pada tahun 2016 sebesar 35,3\% dan pada tahun 2017 meningkat menjadi $37,8 \%{ }^{5}$

Secara teknis, tugas kader yang terkait dengan gizi adalah melakukan pendataan balita, melakukan penimbangan serta mencatatnya dalam Kartu Menuju Sehat (KMS), memberikan makanan tambahan, mendistribusikan vitamin A, melakukan penyuluhan gizi serta kunjungan ke rumah ibu yang menyusui dan ibu yang memiliki balita. Kader diharapkan berperan aktif dan mampu menjadi pendorong, motivator dan penyuluh masyarakat. ${ }^{6}$

Kader adalah seseorang warga desa yang bekerja secara sukarela, ditunjuk serta diangkat berdasarkan kepercayaan dan persetujuan masyarakat. Para kader diharapkan dapat memberdayakan masyarakat agar mampu memecahkan masalah kesehatan masyarakat minimal untuk dirinya dan keluarganya serta untuk masyarakat desa tempatnya tinggal. Namun yang dilematis adalah satu sisi kader diharapkan dapat menjalankan perannya dengan baik, tetapi pengetahuan dan kemampuan kurang memadai di bidang kesehatan salah satunya tentang gizi dan insentif dan dukungan moril juga kerap menjadi salah satu penghambat kinerja para Kader, ${ }^{6}$, serta pendidikan rata rata kader tidak terlalu tinggi, di daerah yang jauh dari pusat kota, masih ditemukan kader dengan pendidikan yang relative rendah, lulusan SMP atau sedikit yang lulus SMA dan masih banyak kader kader yang berusia tua. Tidak terlalu mudah mencari pengganti dari kader-kader senior tersebut, karena para kader senior sudah sangat banyak berjasa bagi perkembangan desa.

Kader diharapkan dapat menjembatani antara petugas/ahli kesehatan dengan masyarakat serta membantu masyarakat mengidentifikasi dan menghadapi/menjawab kebutuhan kesehatan mereka sendiri. Kader juga di harapkan dapat menyediakan informasi bagi pejabat kesehatan berwenang yang mungkin tidak dapat mencapai masyarakat langsung, serta mampu mendorong para pejabat kesehatan di sistem kesehatan agar mengerti dan merespons kebutuhan masyarakat. ${ }^{6}$

Kader dapat membantu mobilisasi sumber daya masyarakat, mengadvokasi masyarakat serta membangun kemampuan lokal, maka kader harus mempunyai pengetahuan yang baik agar tugas 
tugas teknis di lapangan bersama masyarakat dapat terlaksana dengan baik, terutama pengetahuan tentang 1000 HPK.

\section{METODE PENELITIAN}

Jenis penelitian yang digunakan adalah explanatory research dengan pendekatan cross sectional. Variabel terikat pada penelitian ini adalah pengetahuan kader tentang $1000 \mathrm{HPK}$, dan variable bebasnya adalah lama mengabdi, pendidikan dan usia. Populasi dalam penelitian ini adalah seluruh kader posyandu di Desa Cigeulis sebanyak 19 orang. Teknik pengambilan sample adalah total sampling, sehingga jumlah sampel adalah 19 orang Kader di Desa Cigeulis Kabupaten Pandeglang Banten. Data yang diambil adalah data primer. Data primer diperoleh secara langsung dari responden melalui kuesioner yang telah dibuat oleh peneliti yang mengacu pada kerangka konsep penelitian dengan bentuk pertanyaan dengan memilih alternatif jawaban yang telah disediakan.

Analisis univariat dilakukan dengan membuat tabel tabulasi frekuensi. Analisis bivariat dilakukan terhadap dua variabel yang diduga berhubungan, yaitu dengan Chi square. Untuk melihat adanya hubungan di lakukan dengan membandingkan $p$ value dan $\alpha(0,05)$, jika $P$ value $<0,05$ maka dapat disimpulkan adanya hubungan.

\section{HASIL PENELITIAN \\ Pengetahuan responden}

Tabel 1. Pengetahuan responden tentang 1000 HPK

\begin{tabular}{ccc}
\hline Kategori & $\mathrm{n}$ & Persentase $(\%)$ \\
\hline Baik (> Mean) & 6 & 31,6 \\
Kurang Baik (<= Mean) & 13 & 68,4 \\
\hline Total & 19 & 100 \\
\hline
\end{tabular}

Pada tabel 1 diketahui bahwa responden dengan pengetahuan baik berjumlah 6 responden $(31,6 \%)$ dan responden dengan pengetahun kurang baik berjumlah 13 responden $(68,4 \%)$.

\section{Masa mengabdi menjadi kader}

Tabel 2. Masa mengabdi menjadi kader

\begin{tabular}{ccc}
\hline Kategori & $\mathrm{n}$ & Persentase $(\%)$ \\
\hline Lama $(>5$ Tahun$)$ & 12 & 63,2 \\
Baru (<=5 tahun) & 7 & 36,8 \\
\hline Total & 19 & 100 \\
\hline
\end{tabular}

Pada tabel 2 diketahui bahwa responden dengan masa menjadi kader dengan kategori lama berjumlah 12 responden $(63,2 \%)$ dan responden dengan masa menjadi kader kategori baru berjumlah 7 responden $(36,8 \%)$.

\section{Pendidikan responden}

Tabel 3. Pendidikan responden

\begin{tabular}{ccc}
\hline Kategori & $\mathrm{n}$ & Persentase $(\%)$ \\
\hline Tinggi (>= SMA) & 5 & 26,3 \\
Rendah (<SMA) & 14 & 73,7 \\
\hline Total & 19 & 100 \\
\hline
\end{tabular}

Pada tabel 3 diketahui bahwa responden dengan pendidikan tinggi berjumlah 5 responden (26,3\%) dan responden dengan pendidikan rendah berjumlah 14 orang $(73,7 \%)$. 


\section{Usia responden}

Tabel 4. Usia responden

\begin{tabular}{ccc}
\hline Usia & $\mathrm{n}$ & Persentase $(\%)$ \\
\hline Usia Matang $(>=30$ tahun $)$ & 16 & 84,2 \\
Usia belum matang $(<30$ tahun $)$ & 3 & 15,8 \\
\hline Total & 19 & 100
\end{tabular}

Pada tabel 4 diketahui bahwa responden dengan usia matang berjumlah 16 responden $(84,2, \%)$ dan responden dengan usia belum matang berjumlah 3 responden $(15,8 \%)$.

\section{Hubungan pendidikan dengan pengetahuan kader tentang 1000 HPK}

Tabel 5. Hubungan pendidikan dengan Pengetahuan kader tentang 1000 HPK

\begin{tabular}{|c|c|c|c|c|c|c|c|c|}
\hline \multirow{3}{*}{ Pendidikan } & \multicolumn{6}{|c|}{ Pengetahuan } & \multirow{3}{*}{ OR } & \multirow{3}{*}{$P$ Value } \\
\hline & \multicolumn{2}{|c|}{ Baik } & \multicolumn{2}{|c|}{ Kurang Baik } & \multicolumn{2}{|c|}{ Total } & & \\
\hline & $\mathrm{n}$ & $\%$ & $\mathrm{n}$ & $\%$ & $\mathrm{n}$ & $\%$ & & \\
\hline Tinggi & 4 & 80,0 & 1 & 20.0 & 5 & 100 & & \\
\hline Rendah & 2 & 14,3 & 12 & 85,7 & 14 & 100 & 24,00 & 0.017 \\
\hline Total & 6 & 31,6 & 13 & 68,4 & 19 & 100 & & \\
\hline
\end{tabular}

Pada tabel 5 dapat disimpulkan bahwa sebagian besar responden yang mempunyai pendidikan tinggi mempunyai pengetahuan yang baik $(80 \%)$ sedangkan responden dengan pendidikan rendah mempunyai pengetahuan baik sebesar $14,3 \%$. Hasil uji statistik memperlihatkan nilai $\mathrm{p}<0,05(\mathrm{p}=0,017)$ yang berarti terdapat hubungan yang bermakna antara tingkat pendidikan responden dengan pengetahuan tentang $1000 \mathrm{HPK}$. Berdasarkan perhitungan risk estimate diperolah nilai Odds Ratio sebesar 24,00 (CI 95\% : 1,689-340,9) artinya responden yang tingkat pendidikan tinggi mempunyai peluang 24 kali lebih besar mempunyai pengetahuan baik daripada responden yang mempunyai pendidikan rendah.

\section{Hubungan lama mengabdi dengan pengetahuan kader tentang 1000 HPK}

Tabel 6. Hubungan lama mengabdi dengan pengetahuan kader tentang 1000 HPK

\begin{tabular}{|c|c|c|c|c|c|c|c|}
\hline \multirow{3}{*}{$\begin{array}{c}\text { Masa } \\
\text { mengabdi }\end{array}$} & \multicolumn{6}{|c|}{ Pengetahuan } & \multirow{3}{*}{$P$ Value } \\
\hline & \multicolumn{2}{|c|}{ Baik } & \multicolumn{2}{|c|}{ Kurang Baik } & \multicolumn{2}{|c|}{ Total } & \\
\hline & $\mathrm{n}$ & $\%$ & $\mathrm{n}$ & $\%$ & $\mathrm{n}$ & $\%$ & \\
\hline Lama & 4 & 33,3 & 8 & 66,7 & 12 & 100 & \\
\hline Baru & 2 & 28,6 & 5 & 71,4 & 7 & 100 & 1,000 \\
\hline Total & 6 & 31,6 & 13 & 68,4 & 19 & 100 & \\
\hline
\end{tabular}

Pada tabel 6 dapat disimpulkan bahwa sebagian besar responden yang mempunyai masa pengabdian baru mempunyai pengetahuan yang kurang baik $(71,4 \%)$ sedangkan responden dengan masa mengabdi lama mempunyai pengetahuan kurang baik sebesar 66,7\%. Hasil uji statistik memperlihatkan nilai $\mathrm{p}>0,05(\mathrm{p}=1,000)$ yang berarti tidak terdapat hubungan antara masa mengabdi responden dengan pengetahuan tentang 1000 HPK. 


\section{Hubungan usia dengan pengetahuan kader tentang 1000 HPK}

Tabel 7. Hubungan usia dengan pengetahuan kader tentang 1000 HPK

\begin{tabular}{|c|c|c|c|c|c|c|c|}
\hline \multirow{3}{*}{ Usia } & \multicolumn{6}{|c|}{ Pengetahuan } & \multirow{3}{*}{$P$ Value } \\
\hline & \multicolumn{2}{|c|}{ Baik } & \multicolumn{2}{|c|}{ Kurang Baik } & \multicolumn{2}{|c|}{ Total } & \\
\hline & $\mathrm{n}$ & $\%$ & $\mathrm{n}$ & $\%$ & $\mathrm{n}$ & $\%$ & \\
\hline Tinggi & 6 & 37,5 & 10 & 37,5 & 16 & 100 & \\
\hline Rendah & 0 & 0 & 3 & 100 & 14 & 100 & 0,517 \\
\hline Total & 6 & 31,6 & 13 & 68,4 & 19 & 100 & \\
\hline
\end{tabular}

Pada tabel 7 dapat disimpulkan bahwa sebagian besar responden yang mempunyai usia kurang matang mempunyai pengetahuan yang kurang baik (100\%) sedangkan responden dengan usia matang mempunyai pengetahuan kurang baik sebesar 37,5\%. Hasil uji statistik memperlihatkan nilai $p>0,05(p=0,517)$ yang berarti tidak terdapat hubungan antara masa mengabdi responden dengan pengetahuan tentang 1000 HPK. Hasil uji statistik memperlihatkan nilai $p>0,05(p=0,517)$ yang berarti tidak terdapat hubungan antara usia responden dengan pengetahuan tentang $1000 \mathrm{HPK}$.

\section{PEMBAHASAN}

\section{Hubungan pendidikan dengan pengetahuan kader tentang 1000 HPK}

Hasil uji Chi-Square yang telah dilakukan diperoleh nilai $\mathrm{p}=0,017$ yang berarti ada hubungan yang bermakna antara pendidikan dengan tingkat pengetahuan kader kesehatan tentang 1000 HPK.

Pengetahuan adalah hasil dari penginderaan manusia, atau hasil tahu seseorang terhadap obyek melalui indera yang dimilikinya yaitu mata, telinga, hidung, dan lainnya. ${ }^{7}$

Seseorang yang menjadi kader secara sukarela mengabdikan dirinya untuk masyarakat, sehingga pendidikan yang dimiliki kader sangat beragam, mulai dari lulus SD sampai ada yang lulus Perguruan tinggi, masyarakat tidak bisa memilih hanya orang yang berpendidikan tinggi saja yang menjadi kader karena selain bersifat sukarela, orang yang berminat untuk menjadi kaderpun jumlahnya sedikit. Sehingga untuk mengoptimalkan kinerja kader yang sudah ada bisa ditingkatkan melalui pendidikan non-formal yaitu penyuluhan atau refresh pengetahuan secara berkala mengenai pengetahuan kesehatan bagi kader Posyandu terutama tentang 1000 HPK.

Adanya hubungan antara tingkat pendidikan dengan tingkat pengetahuan karena tidak dapat dipungkiri bahwa makin tinggi pendidikan seseorang semakin tinggi pula mereka menerima informasi dan pada akhirnya makin banyak pula pengetahuan yang dimilikinya. Sebaliknya jika seseorang tingkat pendidikannya rendah, akan menghambat perkembangan sikap seseorang terhadap penerimaan informasi dan nilai-nilai yang baru diperkenalkan.

Seseorang yang memiliki pendidikan tinggi akan lebih mudah menerima hal baru dan cenderung terbuka, hal ini akan berpengaruh terhadap kemampuan dan pengetahuan seseorang yang lebih baik. ${ }^{3}$ Pengetahuan tidak mutlak diperoleh dari pendidikan formal saja, akan tetapi dapat diperoleh dari pendidikan yang nonformal. Seseorang dengan tingkat pendidikan rendah tidak berarti mutlak berpengetahuan rendah pula dan seseorang dengan tingkat pendidikan tinggi tidak berarti mutlak berpengetahuan baik pula.

Pendidikan adalah suatu kegiatan atau proses pembelajaran untuk mengembangkan atau meningkatkan kemampuan tertentu sehingga sasaran pendidikan itu dapat berdiri sendiri. Tingkat pendidikan turut pula menentukan mudah tidaknya seseorang dalam menyerap dan memahami 
pengetahuan yang mereka peroleh, pada umumnya semakin tinggi pendidikan seseorang semakin baik pula pengetahuanya. ${ }^{8}$

\section{Hubungan masa pengabdian (lama menjadi kader) dengan pengetahuan Kader tentang 1000 HPK}

Hasil uji Chi-Square yang telah dilakukan diperoleh nilai $\mathrm{p}=1,000$, yang berarti bahwa tidak ada hubungan yang bermakna antara Masa Mengabdi menjadi Kader dengan tingkat pengetahuan tentang 1000 HPK. Masa kerja yang lama akan membentuk pola kerja yang efektif karena berhubungan dengan pengalaman. Kader yang mempunyai pengalaman lebih lama akan mempunyai pengetahuan yang banyak. ${ }^{9}$

Tidak adanya hubungan antara masa kerja dan tingkat pengetahuan kader kesehatan tentang 1000 HPK di Desa Cigeulis disebabkan karena dalam aktivitasnya kader kesehatan banyak sekali diberikan edukasi oleh tenaga Kesehatan, sehingga yang lama menjadi kader dimungkinkan lebih banyak ilmu tetapi malah lupa daripada yang belum lama menjadi kader. Seperti yang diketahui bahwa kader berperan secara sukarela sehingga sifat kesukarelaan tersebut kadangkala membuat kader merasa tidak terlalu terikat dengan tugasnya dan dapat bekerja semaunya,

\section{Hubungan Usia dengan pengetahuan Kader tentang 1000 HPK}

Hasil uji Chi-Square yang telah dilakukan diperoleh nilai $\mathrm{p}=0,517$ yang berarti tidak ada hubungan yang bermakna antara usia dengan tingkat pengetahuan kader kesehatan tentang 1000 HPK. Hasil penelitian ini tidak sesuai dengan penelitian Nurayu (2013) di Puskesmas Sidoharjo, Sragen yang menyatakan tidak ada hubungan antara umur dengan tingkat pengetahuan seseorang. Menurut Nurayu (2013), bertambahnya usia maka produktivitasnya juga menurun, hal ini disebabkan keterampilan fisik akan berkurang seiring bertambahan usia, tetapi pengalaman dan kematangan akan semakin meningkat.

Umur terkait dengan kedewasaan berfikir, individu dengan usia dewasa mempunyai pengetahuan yang lebih baik dibandingkan dengan usia yang jauh lebih muda. Usia yang dewasa juga membuat orang mempunyai cara pandang yang matang, lingkungan sosial budaya akan membentuk pengalaman baru pada seseorang. ${ }^{7}$

Seorang kader akan tetap menjadi kader sampai seseorang tersebut memutuskan untuk tidak lagi menjadi kader, karena tidak ada peraturan yang menyebutkan mengenai batasan masa kerja dan usia seseorang dapat menjadi kader, sehingga banyak kader yang sudah berusia lanjut tetapi tetap menjadi seorang kader. Hal ini tidak menutup kemungkinan karena pengetahuan yang ia miliki bisa saja berasal dari pengetahuan yang dimilikinya sebelumnya, pengalaman pribadi maupun orang lain dan beberapa faktor lainnya yang dapat membentuk pengetahuan seseorang dalam jangka waktu yang lama dan akan bertahan sampai usia tua. ${ }^{8}$ Dalam teorinya, usia mempengaruhi perkembangan daya tangkap dan pola pikir seseorang, semakin tua usia seseorang maka daya tangkapnya semakin rendah.

\section{SIMPULAN}

Dari hasil penelitian tentang faktor yang berhubungan dengan pengetahuan kader posyandu tentang 1000 Hari pertama Kehidupan (HPK) didapatkan:

1. Dari 19 responden (kader Posyandu) masih banyak yang mempunyai pengetahuan rendah tentang 1000 HPK sebesar $68,4 \%$.

2. Terdapat hubungan antara pendidikan dengan pengatahuan kader posyandu tentang $1000 \mathrm{HPK}(p$ value $=0.017)$, tidak terdapat hubungan antara usia dengan pengetahuan kader posyandu tentang 1000 HPK. ( $P$ value $=1,000)$, tidak terdapat hubungan antara lama pengabdian dengan pengetahuan kader posyandu tentang $1000 \mathrm{HPK}(P$ value $=0,517)$.

\section{SARAN}

1. Bagi responden, untuk ibu kader posyandu, sebaiknya lebih banyak membaca atau mencari informasi tentang 1000 HPK, karena sangat penting untuk digunakan dalam melakukan 
pemahaman ke masyarakat tentang arti pentingnya 1000 HPK sehingga akan mempengaruhi kesehatan masyarakat terutama untuk ibu dan anak.

2. Bagi puskesmas, dari hasil pengetahuan responden, $68,4 \%$ pengetahuannya kurang baik tentang 1000 HPK, maka sebaiknya puskesmas memberikan penyuluhan/edukasi kepada kader tentang 1000 HPK dengan metode yang efektif karena banyak kader berusia tua dan pendidikan yang rendah.

3. Bagi kesehatan masyarakat dapat membuat Program pengabdian kepada masyarakat tentang 1000 HPK di Desa Cigeulis untuk kader dan masyarakat

\section{DAFTAR PUSTAKA}

1. Republik Indonesia. Kerangka kebijakan gerakan nasional percepatan perbaikan gizi dalam rangka seribu hari pertama kehidupan (Gerakan 1000 HPK). Jakarta:2013

2. Djauhari T. Gizi dan 1000 HPK. Saintika Medika. 2017;13(2):125

3. Dwi Suryani Y. Mengejar periode emas 1000 hari pertama kehidupan anak. Program Magister Pendidikan Anak Usia Dini. Universitas Negeri Jakarta. Tersedia dari : http://pps.unj.ac.id/mengejar-periode-emas-1000-hari-pertama-kehidupan-anak/

4. Kementerian Kesehatan RI. Hasil pemantauan status gizi dan indikator kinerja gizi tahun 2015. Jakarta: Direktorat Gizi Masyarakat. Dirjen Kesmas;2016

5. Kementerian Kesehatan RI. Buku saku pemantauan status gizi tahun 2017. Jakarta: Direktorat Gizi Masyarakat. Dirjen Kesmas;2018;

6. Iswarawanti DN. Kader posyandu: Peranan dan tantangan pemberdayaannya dalam usaha peningkatan gizi anak di Indonesia. Jurnal Manajemen Pelayanan Kesehatan Volume 13 No.4, Desember 2010

7. Nurayu AW. Hubungan tingkat pengetahuan, pendidikan, usia dan lama menjadi kader posyandu dengan kualitas laporan bulanan data kegiatan posyandu. Surakarta: Universitas Muhammadiyah Surakarta; 2013

8. Rahardjo \& Setiyowati. Hubungan tingkat pendidikan dan pengetahuan dengan perilaku keluarga sadar gizi (Kadarzi) pada masyarakat perkotaan dan pedesaan di Kabupaten Banyumas. Kesmasindo [Internet]. 2011;4(2):150-8. Tersedia http://jos.unsoed.ac.id/index.php/kesmasindo/article/view/21/23

9. Profita AC. Beberapa Faktor yang berhubungan dengan keaktifan kader posyandu di Desa Pengadegan Kabupaten Banyumas. Jurnal Administrasi Kesehatan Indonesia volume 6 No.3. 2018;6(2):68. 